\title{
Koneksi IP Publik Via L2TP (IPSec) Pada Windows 10
}

\author{
Muhammad Ullil Fahri \\ muhammad.fahri001@binus.ac.id \\ https://ullilfahri.skb.ovh/
}

Sebuah kantor atau kampus memiliki server. Tetapi sangat di sayangkan penggunaan server hanya bisa di akses secara lokal saja. Sangat di sayangkan server yang mahal tapi tidak bisa di akses di luar jaringan. Pada tulisan ini akan memberikan anda tutorial cara melakukan koneksi IP Publik lewat Windows 10. sehingga server dapat di akses dari manapun dan kapanpun.

Artikel ini akan menjelaskan bagaimana Anda dapat mengkonfigurasi L2TP / IPsec VPN di Windows 10 [1].

\section{Sarat :}

- Windows 10

- Acees Full

\section{Langkah Pertama}

Silahkan anda login ke Windows 10 kamu. Klik pada ikon pencarian di bilah menu Windows dan cari panel kontrol. Anda harus melihat ikon Control Panel dan mengkliknya.

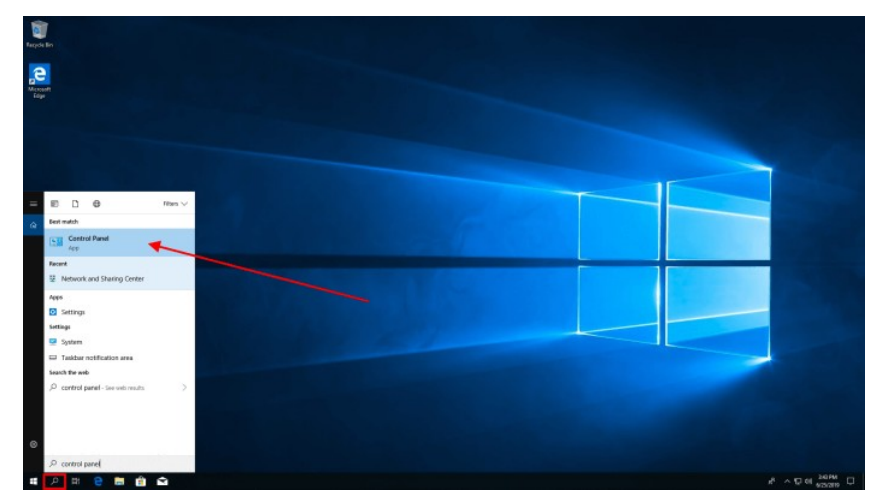

Langkah Kedua

Click on Set up a new connection on a network

Open Network and Internet

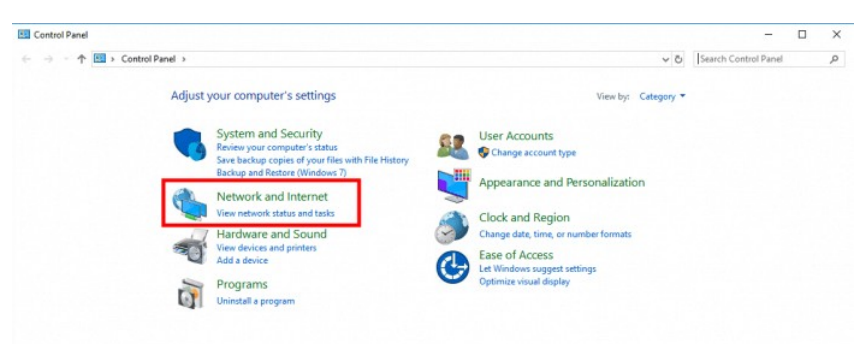

Open Network and Sharing Center

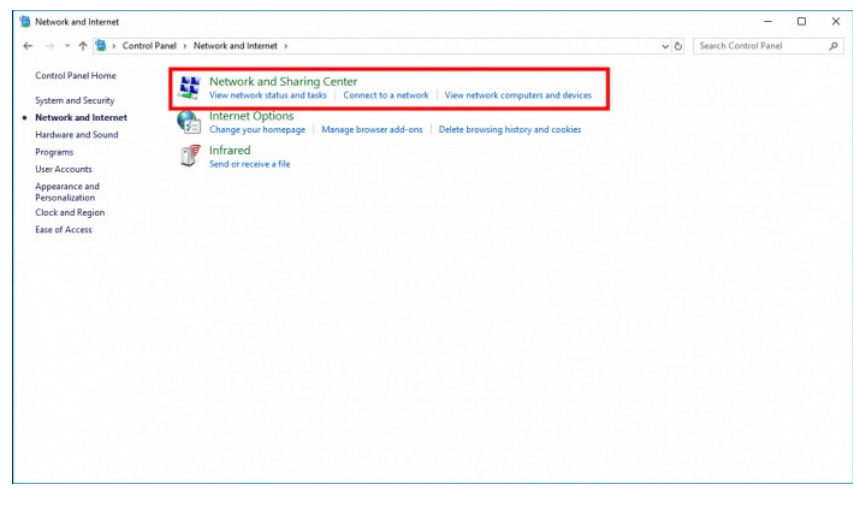




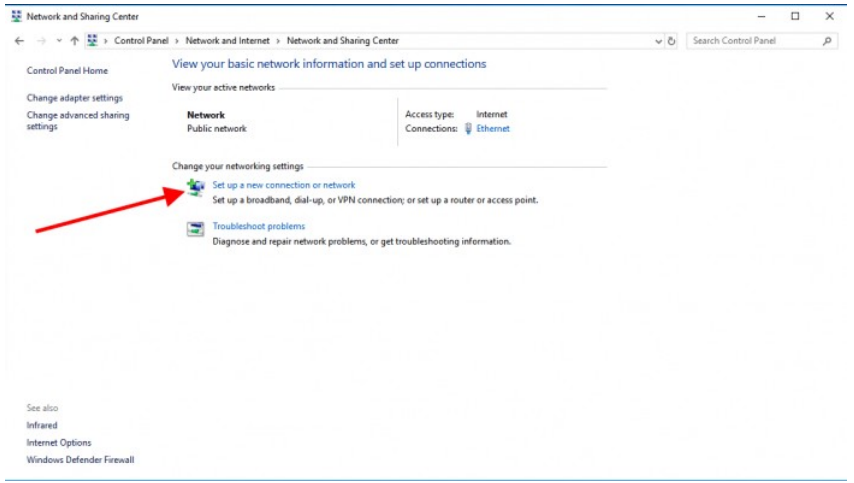

Select Connect to a workplace and click on Next

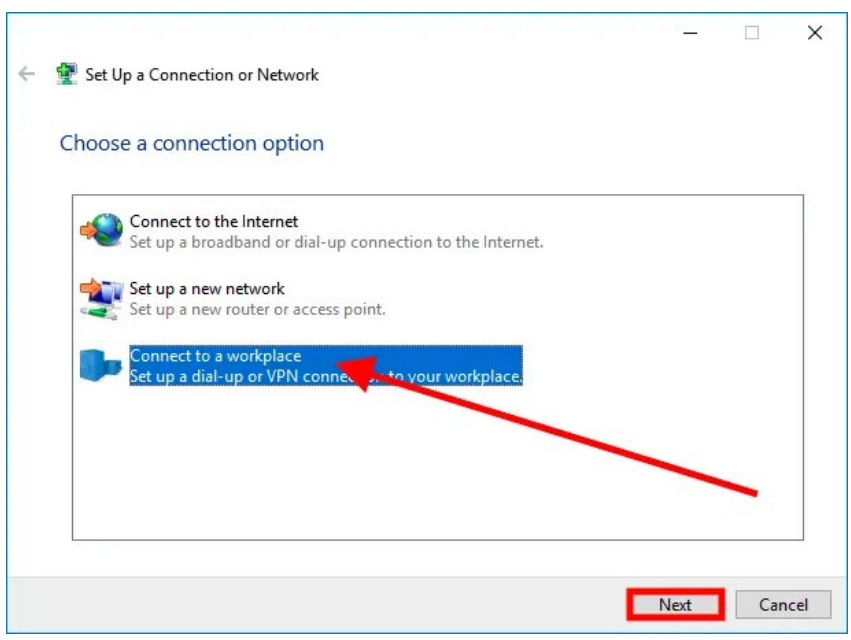

Click Use my Internet connection (VPN)

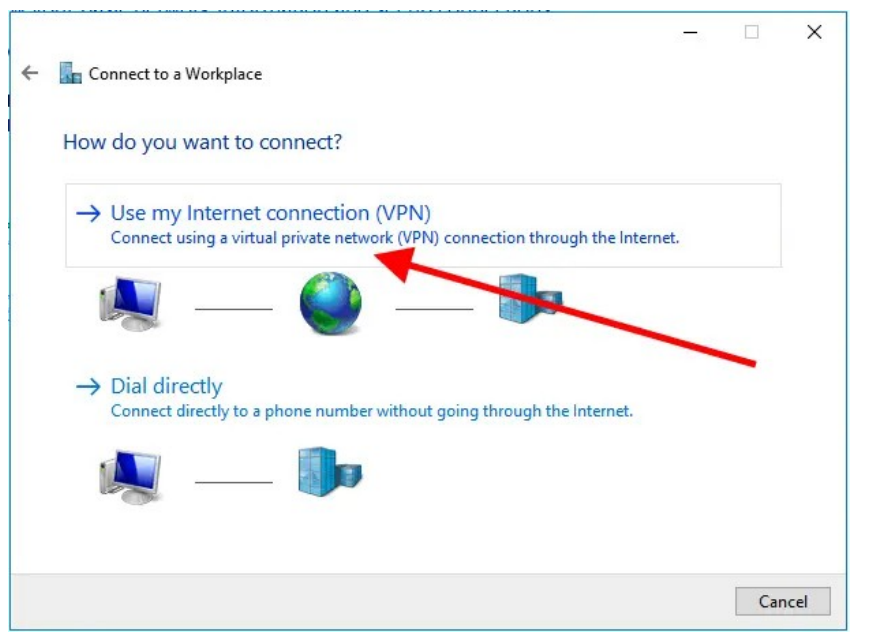

Masukan IP Publik yang disudah diberikan sebelumnya.

\section{Contoh IP Publik : 193.33.61.185}

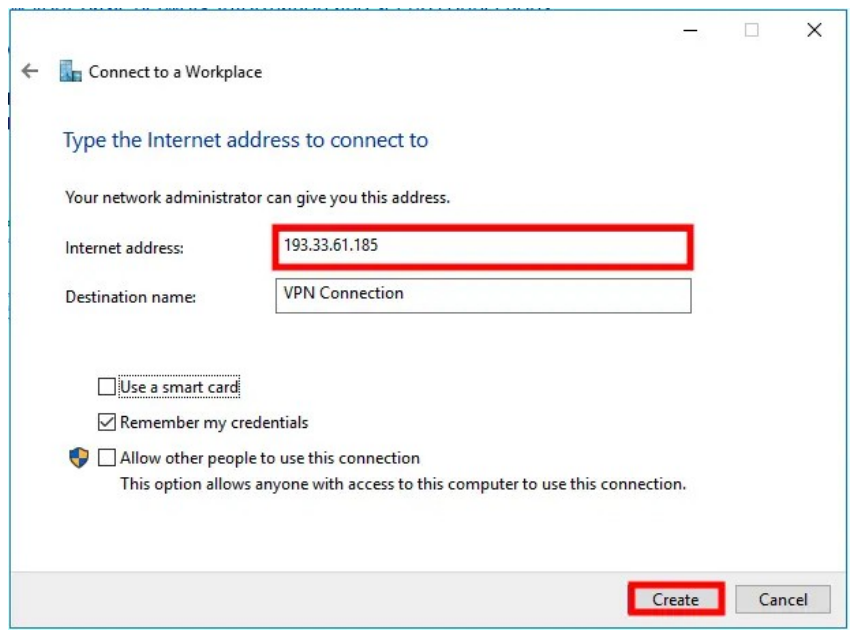

Setelah Anda mengklik Buat wizard penyiapan akan ditutup.

Klik Ubah pengaturan adaptor di menu sebelah kiri.

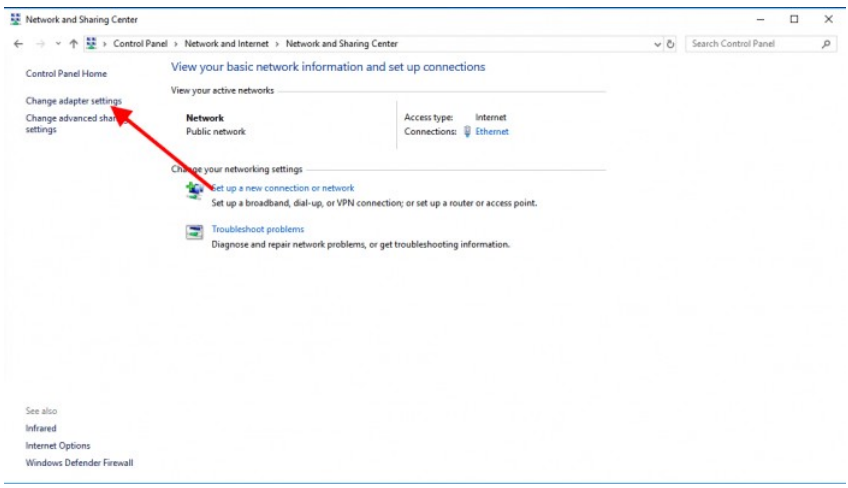

Anda sekarang akan melihat semua antarmuka yang tersedia. Buka Properti antarmuka koneksi VPN 


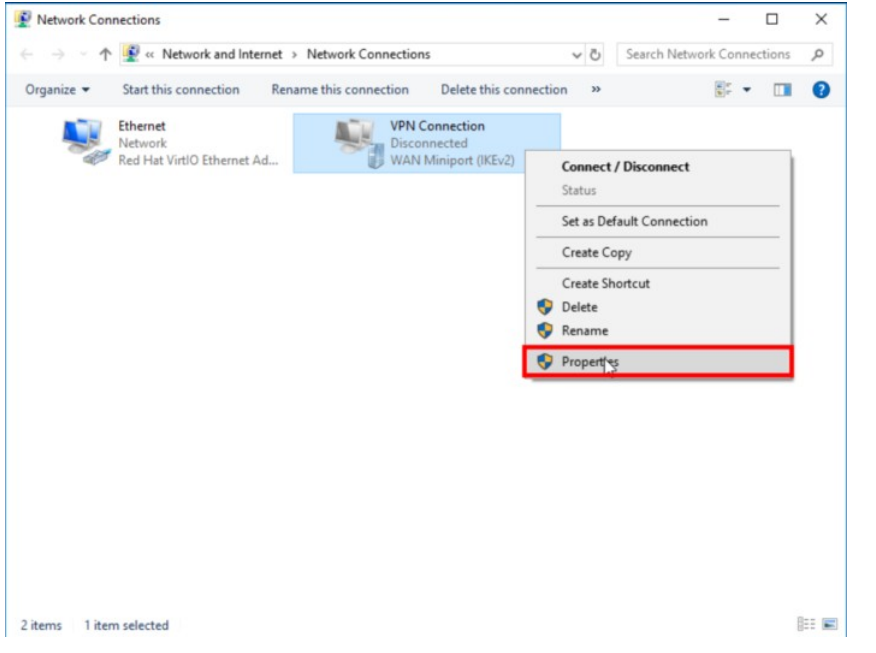

Open Security tab

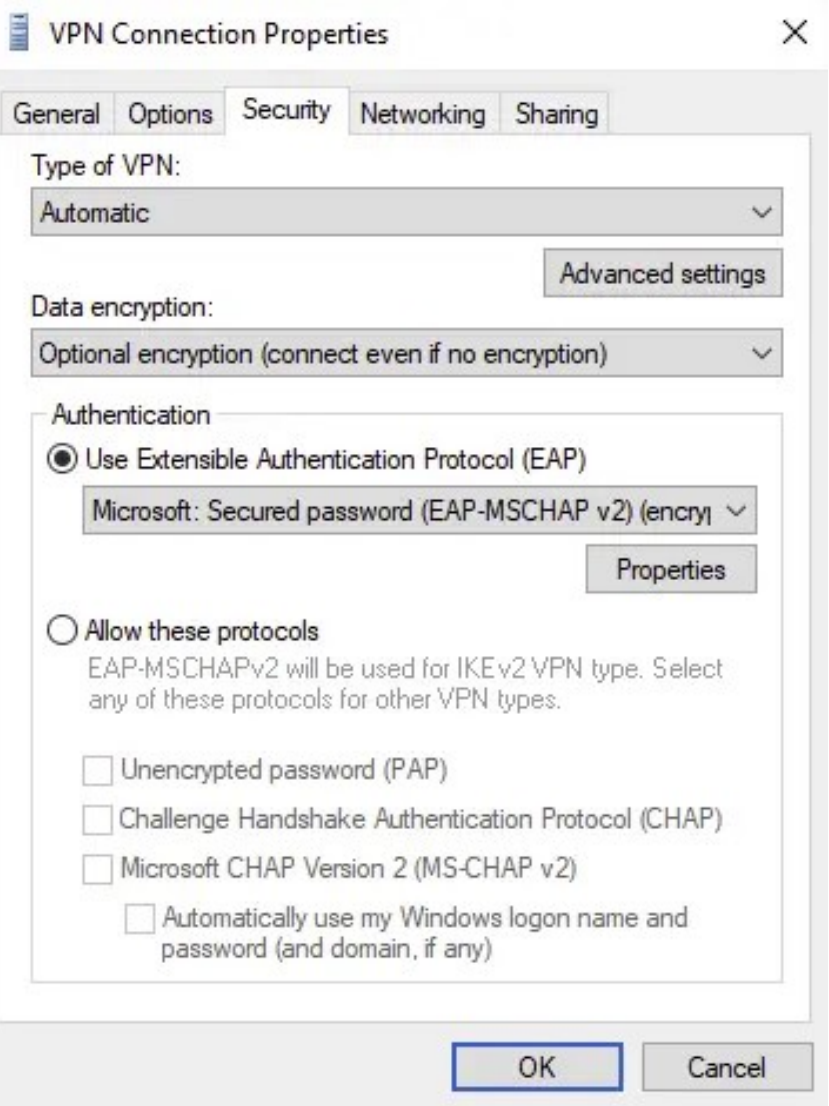

Open dropdown of Type of VPN and select Layer 2 Tunneling Protocol with IPsec (L2TP/Ipsec)

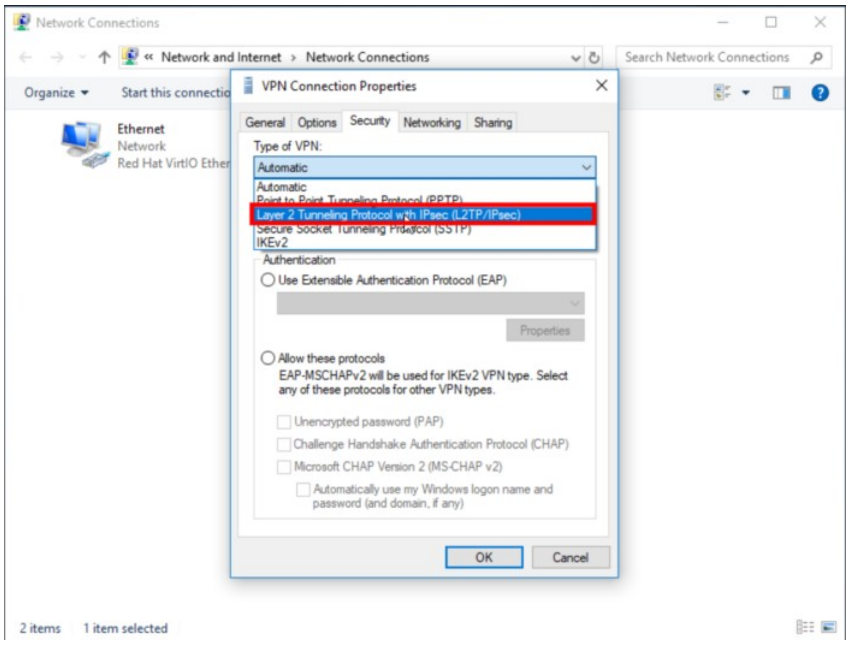

Click on Advanced settings. Select Use preshared key for authentication and fill in the preshared key which you created on the Windows Server. Apply it by clicking on OK.

Masukan Key yang sudah saya berikan sebelumnya.

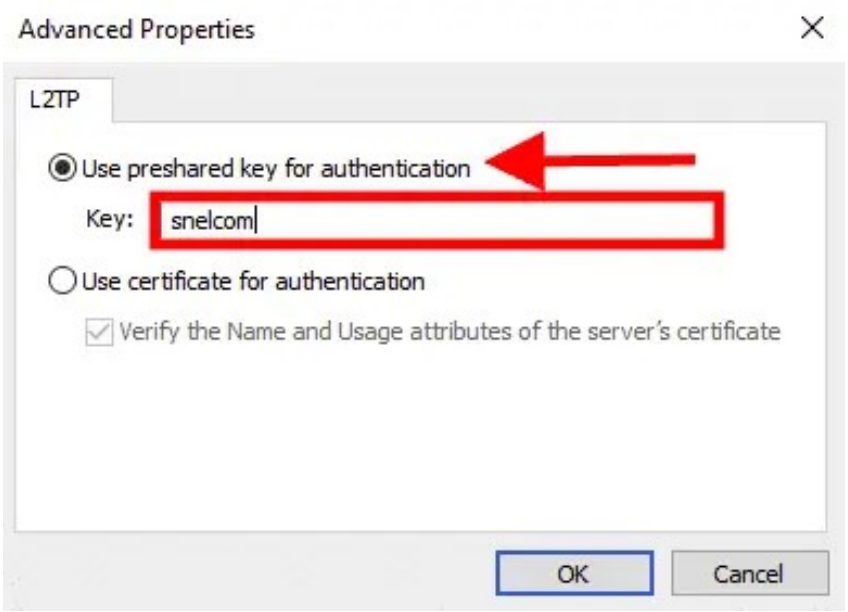

Kembali ke tab Keamanan. Pilih Izinkan protokol ini dan periksa nilai berikut:

- Challenge Handshake Authentication Protocol (CHAP) 
- Microsoft CHAP Version 2 (MS-CHAP v2)

- VPN Connection Properties

$\times$

\begin{tabular}{l} 
General Options Security Networking Sharing \\
Type of VPN: \\
Layer 2 Tunneling Protocol with IPsec (L2TP/IPsec) \\
\hline Advanced settings
\end{tabular}

Data encryption:

Optional encryption (connect even if no encryption)

- Authentication

Use Extensible Authentication Protocol (EAP)

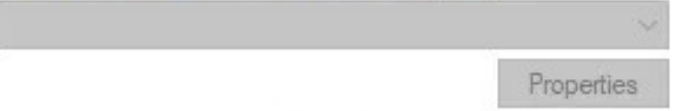

- Allow these protocols

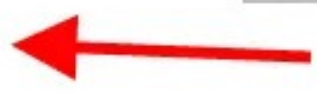

Unencrypted password (PAP)

$\square$ Challenge Handshake Authentication Protocol (CHAP)

$\checkmark$ Microsoft CHAP Version 2 (MS-CHAP v2)

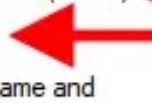

Automatically use my Windows logon name and password (and domain, if any)

\section{OK Cancel}

Apply the changes by clicking on OK.
VPN Connection Properties

$\times$

General Options Security Networking Sharing

Type of VPN:

Layer 2 Tunneling Protocol with IPsec (L2TP/IPsec)

Data encryption:

Advanced settings

Optional encryption (connect even if no encryption)

Authentication

Use Extensible Authentication Protocol (EAP)

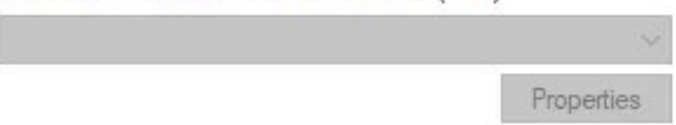

Allow these protocols

Unencrypted password (PAP)

$\square$ Challenge Handshake Authentication Protocol (CHAP)

$\square$ Microsoft CHAP Version 2 (MS-CHAP v2)

Automatically use my Windows logon name and password (and domain, if any)

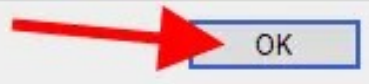

Cancel

\section{Langkah Ketiga}

Mulai lakukan Koneksi Ke L2TP Server

Buka ikon Jaringan di kanan bawah dan klik Koneksi VPN

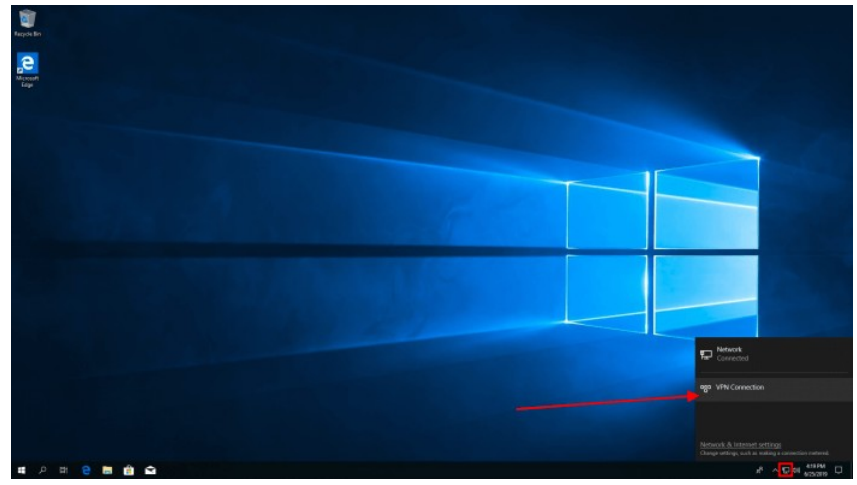

Setelah Anda mengklik Koneksi VPN, tombol Connect akan terlihat. Klik Hubungkan 


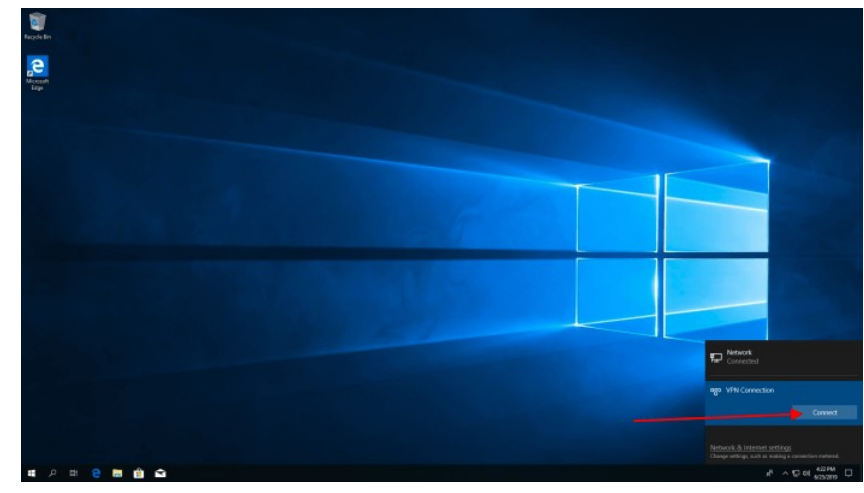

Anda akan diminta untuk memasukkan nama pengguna dan kata sandi

\begin{tabular}{l} 
Windows Security \\
Sign in \\
\begin{tabular}{|c|}
\hline User name \\
\hline Password \\
\hline \\
\hline
\end{tabular} \\
\hline
\end{tabular}

Silahkan masukan Usarname dan Password yang sudah saya berikan.

Mencoba menyambungkan.

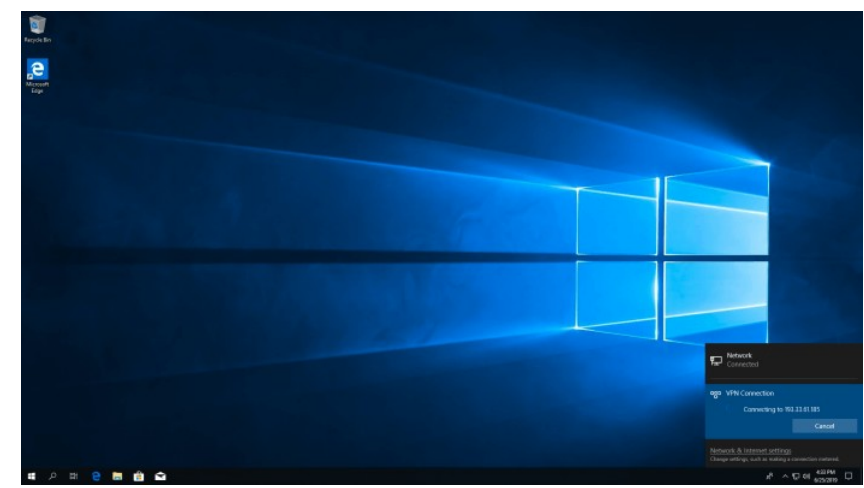

Koneksi VPN IP Publik Anda berhasil dibuat.

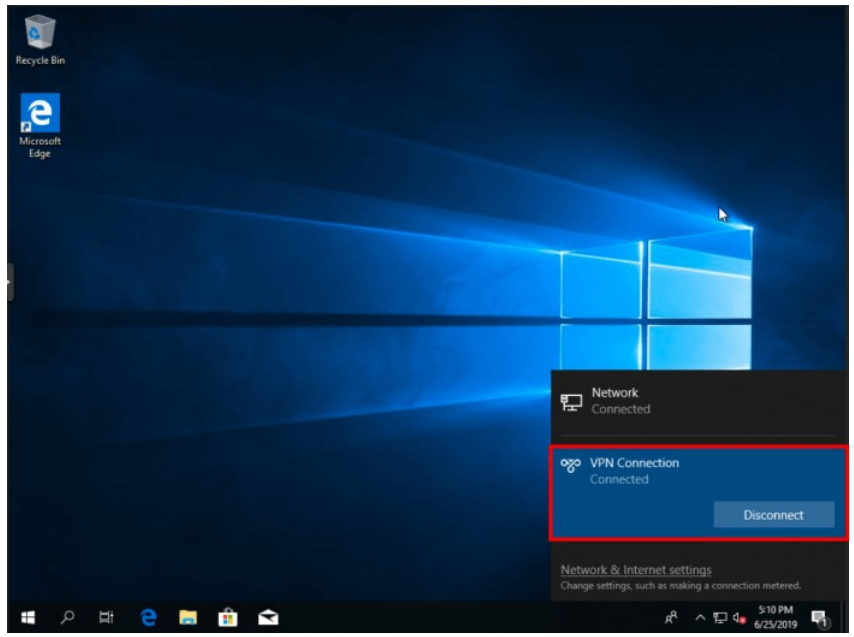

\section{Langkah Keempat}

Lakukan Koneksi IP Publik.

Silahkan Koneksi pada jaringan lain dengan Contoh IP Publik : 193.33.61.185.

Jika di server sudah terinstall web server atau aplikasi sever secara otomatis ketika port 80 terbuka langsung dapat di akses.

Jika anda memerlukan IP Publik, Silahkan Hubungi saya ya. 


\section{DAFTAR PUSTAKA}

[1] Snel, "Learn how to connect L2TP/IPsec VPN on Windows 10.” https://www.snel.com/support/learn-how-to-connect-l2tp-ipsec-vpn-on-windows-10/. 